\title{
New Differential Protection for Variable Speed Doubly Fed Induction Machines
}

\author{
M. E. Zarei, C. A. Platero, C. Veganzones and J. R. Arribas
}

\begin{abstract}
This paper presents a novel differential protection for the variable speed doubly fed induction machines (DFIMs), which typically are working as a generator in wind turbine systems and working as motor/generator in pump storage hydropower plants. The proposed protection, which is based on the comparison of the vector components Id-Iq of the rotor and stator currents, can protect the whole induction machine during the internal faults. This protection considers the dynamic variation of the rotor frequency and the extremely low rotor frequency along the different operation points of the DFIM. The proposed relay is validated in Matlab Simulink environment for a 2 MW DFIM, and the results show that the proposed differential protection protects effectively the entire induction machine during internal faults.
\end{abstract}

Index Terms--Variable speed Doubly Fed Induction machine (DFIM), Differential protection, Wind turbine generation, hydroelectric power generation.

\section{NOMENCLATURE}

$\mathrm{P}_{\mathrm{s}}, \mathrm{Q}_{\mathrm{s}}$

$\mathrm{R}_{\mathrm{s}}, \mathrm{R}_{\mathrm{r}}$

$\vec{V}_{S}$

$\mathrm{V}_{\text {sd, }}, \mathrm{V}_{\mathrm{sq}}$

$\mathrm{V}_{\text {rd, }}, \mathrm{V}_{\text {rq }}$

$\varphi_{s d}, \varphi_{s q}$

$\varphi_{r d}, \varphi_{r q}$

$\mathrm{i}_{\mathrm{sd}}, \mathrm{i}_{\mathrm{sq}}$

$\mathrm{i}_{\mathrm{rd}}, \mathrm{i}_{\mathrm{rq}}$

$\mathrm{I}_{\text {diff_d }}, \mathrm{I}_{\text {diff_q }}$

Idiff_d set, $_{\text {diff_q set }}$

$\mathrm{L}_{\mathrm{m}}$

$\mathrm{L}_{\mathrm{s}}, \mathrm{L}_{\mathrm{r}}$

$\omega_{\mathrm{s},} \omega_{\mathrm{r}}$

$\mathrm{N}$
Stator active and reactive power

Stator and rotor resistance

Stator voltage vector

Stator voltage in synchronous frame Rotor voltage in synchronous frame Stator flux in in synchronous frame rotor flux in in synchronous frame

Stator current in synchronous frame rotor current in synchronous frame Differential current of stator and rotor current in synchronous frame

Differential current setting in synchronous frame

Mutual inductance

Stator and rotor inductance

synchronous and rotor angular frequency

Turn numbers ratio of stator and rotor winding

\section{INTRODUCTION}

$\mathrm{E}$ LECTRIC machines should use protection relays in

M. E. Zarei, C. A. Platero Gaona, C. Veganzones Nicolás, and J. Rodríguez Arribas are with the Department of Electrical Engineering, Escuela Tecnica Superior de Ingenieros Industriales, Universidad Politecnica de Madrid, 28006 Madrid, Spain (e-mail: me.zarei@alumnos.upm.es; carlosantonio.platero@upm.es; carlos.veganzones@upm.es; jaime.rodriguez@upm.es ) order to safeguard them against abnormal operations or faults, as short circuits or overloads. These situations could be dangerous both for the facilities and for the operators [1].

The rotor wound-asynchronous machine is a well-known machine, traditionally used as motor for high torque starting loads. The use of this machine has been considerably increased recently thanks to the expansion of the wind energy, and the large-size variable speed pumped storage power plants.

The increasing importance of wind energy worldwide has originated the development of generators specially designed for this application. In order to increase the wind energy production, it is important that the generator could modify the rotation speed. Thus, a great part of the wind generators manufactured today are doubly fed induction generators (DFIG), since they can vary the speed thanks to a reduced size power converter [2-4].

Large-scale integration of renewable energy, especially wind power, is a problem for the power system operators, as the wind behavior is random. As a consequence, it is necessary to have back-up generators in case of lack of wind appears. On the other hand, in case of high wind and low power consumption, it could be necessary to store the excess of energy, making the energy storage necessary for a safety power system operation [5-6].

Nowadays, thanks to its larger capacity and its high efficiency, pumped storage hydropower plants are the most suitable back-up generators for wind-power integration [7].

Traditionally pumped storage power plants had not the possibility to vary the power while working in pumping mode, but nowadays the variable speed pumping units allow the power regulation both in turbine and pumping mode with an excellent efficiency. Most of these large alternators are based on DFIM with a rotor converter and there are not many protections for this type of machine, especially for the rotor.

The rotor windings of a variable speed DFIM are connected to a back-to-back converter and the rotor current frequency generally is between $0.1 \mathrm{~Hz}$ and $6 \mathrm{~Hz}$ during normal operation for hydroelectric power generation [8-9], and is between 0 to $20 \mathrm{~Hz}$ for the wind turbine generation [10].

Many researches are focused on the grid fault near the stator of the doubly fed induction machine, since in this case an over current and over voltage will be appear in the rotor side converter (RSC) [11-17]. Many solutions, which are based on hardware solution and control modification have been presented to overcome the problems of external fault in the stator [11-16]. For example, demagnetization strategy [12], employing a crowbar [13], or using a STATCOM [14] 
or a dynamic voltage restorer (DVR) [15], are some of these solutions in order to reduce the fault current. However, the objective of these solutions is to protect the converter and the machine during over current.

Generally, the DFIMs are protected only from the stator windings, as mentioned, and there is no specific protection for the rotor in the market. However, in recent years, some investigation started in order to develop a new protection relay that covers the entire machine. Hence, in [8-9], a protection relay was proposed for DFIM of pump storage plants to protect the entire machine, in which the peak and RMS current values were used in order to have a fast protection for the machine. However, the implemented solution given for this protection is complicated.

One of the most effective protections used in power system and particularly in electrical machines is the differential protection. This protection is based on the comparison of two or more currents and it detects internal faults. Differential protections are extendedly used in power systems such as lines, cables, bus bars and in all types of machines like transformers, induction and synchronous machines [18-19].

In rotating machines, induction or synchronous, the differential protection only protects the stator windings through the comparison of the currents at both endings of the windings. To the best knowledge of the authors, the differential protection was not used to protect the entire DFIM machine until now.

This paper presents a novel and simple differential protection for doubly fed induction machines; the main advantage of this new protection is that the rotor and the stator are protected during different operation speeds, and the implementation of this protection is simple.

This paper is structured as follows: Section III presents the operating principle of the differential protection. Section IV presents the operation principle of the new protection for the doubly fed induction machine presented. The section $\mathrm{V}$ analyses the results of the simulations, and finally section VI presents the conclusions of this work.

\section{DIFFERENTIAL STATE OF THE ART}

The differential protection is a very common protection used in a large range of electrical devices, especially in electrical machines. Its operation principle is based in the comparison of the input and output currents in each phase winding, as expressed in (1), where the differential current $I_{\text {diff }}$ is calculated.

$$
I_{\text {diff }}=\left|\vec{I}_{T}-\vec{I}_{N}\right|
$$

The restraining current, $I_{b}$ is obtained using different expressions, depending on the relay manufacturer, but the most commonly used expression is shown in (2), where $\mathrm{T}$ and $\mathrm{N}$ denotes terminal side and neutral side respectively, and || means phasor magnitude.

$$
I_{b}=\frac{\left|\vec{I}_{T}\right|+\left|\vec{I}_{N}\right|}{2}
$$

The most commonly used differential protection algorithm is based on a dual slope, or multiple slope characteristics, where the differential current $I_{\text {diff }}$ and the restraining current $\mathrm{I}_{\mathrm{b}}$ are compared.

The simplified schematic of a differential protection for motors and generators is shown in Fig. 1.



Fig. 1. Simplified schema of a motor/generator differential protection.

For correctly obtaining $\mathrm{I}_{\text {diff }}$ and $\mathrm{I}_{\mathrm{b}}$, numerical protective systems filter digitally the input currents, and obtain the phasor magnitudes using Fourier filters. In this case only the stator is protected.

For transformers protection, the differential algorithm is more complex, basically because the protection should compensate the vector group of the transformer and the inrush current.

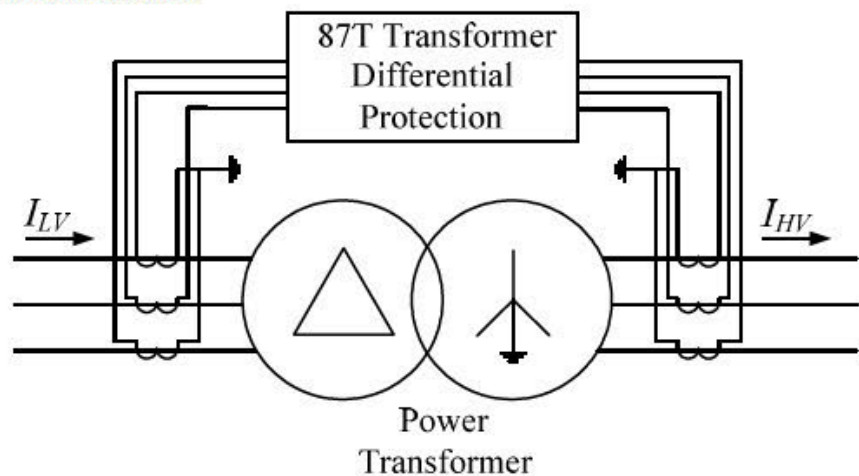

Fig. 2. Simplified schema of a transformer differential protection.

The differential protection for a transformer is shown in Fig. 2. In this figure the high voltage currents and the low voltage currents are compared according to the winding turn numbers of the transformer.

\section{NOVEL DIFFERENTIAL PROTECTION FOR DFIM}

\section{A. Basic principles of DFIM}

The dynamic model of a DFIM in the synchronous frame is shown in Fig. 3. According to this figure, the stator active and reactive power can be presented as follows [20]: 


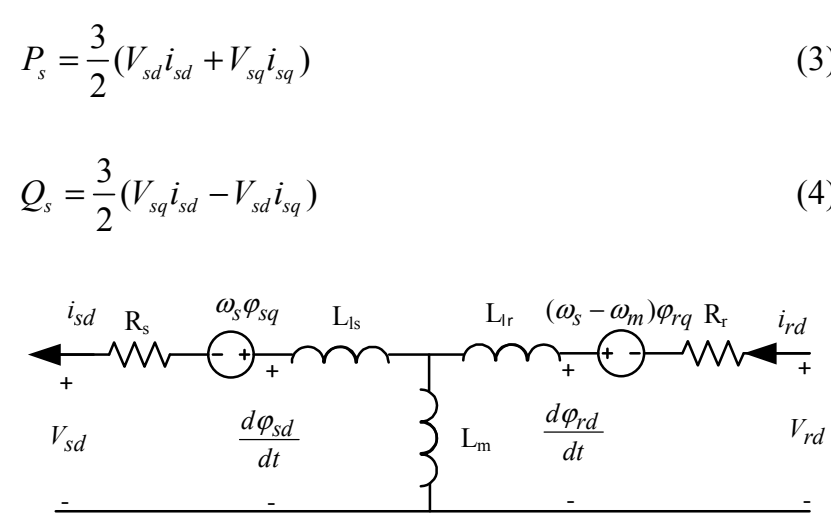

(a)

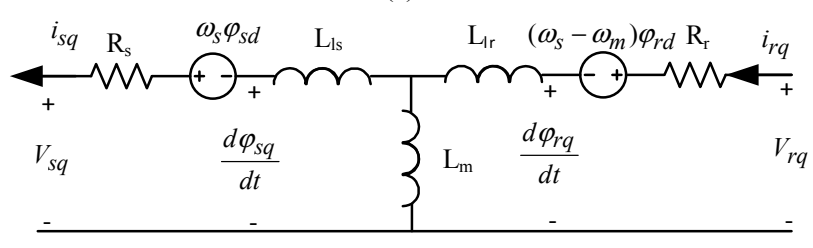

(b)

Fig.3. Dynamic model of DFIM in synchronous frame: (a) d axis, (b) q axis

If a voltage oriented control (VOC) is employed, the stator voltage will be along the $\mathrm{d}$ axis in the synchronous frame. Therefore, the stator flux could be shown as:

$$
\begin{aligned}
& \varphi_{s d}=0=L_{m} i_{r d}-L_{s} i_{s d} \\
& \varphi_{s q}=-\frac{V_{s d}}{\omega_{s}}=L_{m} i_{r q}-L_{s} i_{s q}
\end{aligned}
$$

The relation between the stator current and the rotor current in the synchronous frame in a VOC system, can be presented as:

$$
\begin{aligned}
& i_{r d}=\frac{L_{s}}{L_{m}} i_{s d} \\
& i_{r q}=-\frac{\left|\vec{V}_{S}\right|}{\omega_{s} L_{m}}+\frac{L_{s}}{L_{m}} i_{s q}
\end{aligned}
$$

The differential current in the synchronous frame can be estimated as:

$$
\begin{aligned}
& \left|i_{r d}-i_{s d}\right|=\left(\frac{L_{s}}{L_{m}}-1\right) i_{s d} \\
& \left|i_{r q}-i_{s q}\right|=\left|-\frac{\left|\vec{V}_{S}\right|}{\omega_{s} L_{m}}+\left(\frac{L_{s}}{L_{m}}-1\right) i_{s q}\right|
\end{aligned}
$$

Since the leakage inductance is much smaller than the mutual inductance, especially for big induction machines, $\frac{L_{s}}{L_{m}}$ is consider be equal to 1 . Hence, the differential current of rotor and stator in $\mathrm{d}$ and $\mathrm{q}$ axis will be:

$$
\begin{aligned}
& \left|i_{r d}-i_{s d}\right| \approx 0 \\
& \left|i_{r q}-i_{s q}\right| \approx\left|\frac{\left|\vec{V}_{S}\right|}{\omega_{s} L_{m}}\right|
\end{aligned}
$$

As a result, during normal operation the differential current in $\mathrm{d}$ axis has a small value, and in $\mathrm{q}$ axis is almost equal to the magnetization current of the machine.

\section{B. Proposed Differential Protection for DFIM}

The block diagram of the proposed differential protection for DFIM is shown in Fig. 4.

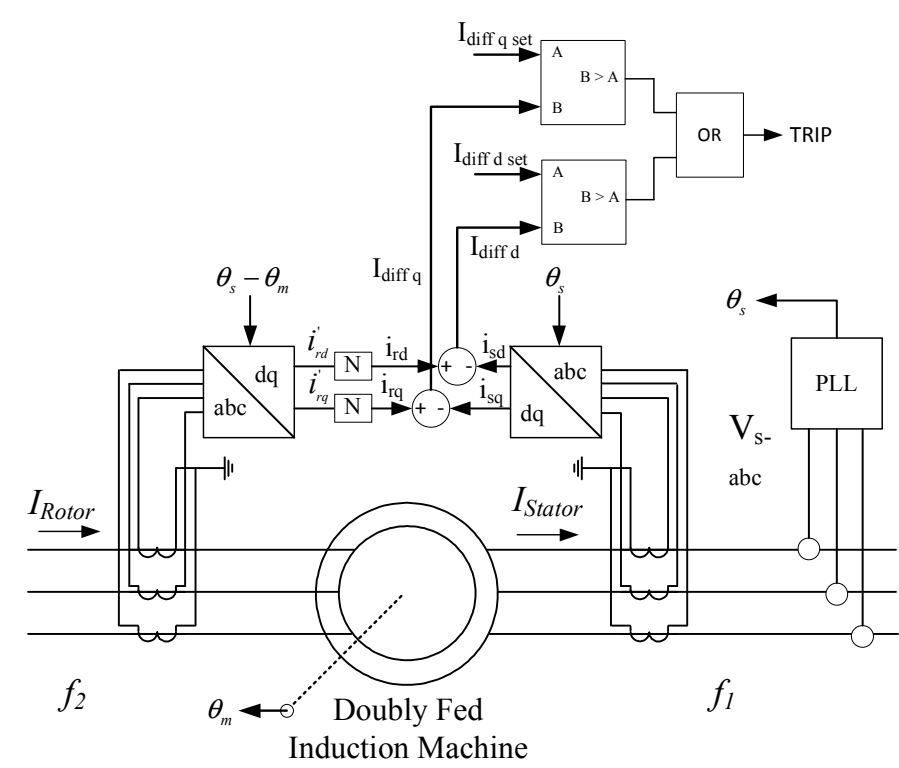

Fig. 4. Simplified schema of a DFIM differential protection.

A phase locked loop (PLL) is used in order to detect the stator voltage phase position. This angle $\left(\theta_{S}\right)$ is needed to convert the three-phase stator current to $\mathrm{dq}$ synchronous frame. Moreover, the difference between the stator voltage angle and the electric rotor angle $\left(\theta_{m}\right)$ is utilized to convert the rotor current to the synchronous frame $\left(i_{r d}, i_{r q}\right)$.

Then, the rotor current is referred to the stator by multiplying by the turns ratio of stator and rotor windings (N). The rotor and stator currents in the synchronous frame are compared, and differential $\mathrm{d}$ and $\mathrm{q}$ currents are obtained ( $I_{\text {diff_d }}, I_{\text {diff_q }}$ ). Finally, these differential currents are compared to the settings ( $\left.\mathrm{I}_{\text {diff_d set, }} \mathrm{I}_{\text {diff_a set }}\right)$ and the machine would be tripped if any of the differential currents were larger than the settings.

\section{SimUlation RESUltS}

In order to evaluate the performance of the proposed differential protection for the DFIM, 4 fault cases have been studied for a 2 MW DFIM using Matlab Simulink. The parameters of the simulated DFIM are included in the appendix. For all the cases in this study, the DFIM was working as a generator and the stator was injecting $1.5 \mathrm{MW}$ and 0 Mvar. The generator speed in this case was considered to be fixed at $1.1 \mathrm{p} . \mathrm{u}$. due to the big inertia of the wind turbine (working in the hyper synchronous speed). There are many different control strategies for the Rotor Side Converter (RSC) of DFIM such as vector controls, predictive controls, direct power controls, sliding mode, etc. Many papers have addressed different strategies and improved RSC strategies for the low voltage ride through for DFIM when 
there is a fault in the grid in order to overcome the problems. However, the objective of this paper is to investigate the performance of the differential current protection. Hence, the RSC was controlled under fixed $V_{d}$ and $V_{q}$ commands during the simulations. In this paper, the three-phase fault has been considered in all the simulations. The four fault cases that have been studied are the following:

1- External three-phase fault between the rotor side converter and the rotor winding: from $t=1 \mathrm{~s}$ until $\mathrm{t}=1.2 \mathrm{~s}$

2- Internal three-phase fault in the rotor windings: from $\mathrm{t}=2 \mathrm{~s}$ until $\mathrm{t}=2.2 \mathrm{~s}$

3- Internal three-phase fault in the stator winding: from $\mathrm{t}=3 \mathrm{~s}$ until $\mathrm{t}=3.2 \mathrm{~s}$

4- External three-phase fault in the grid: from $t=4.0 \mathrm{~s}$ until $\mathrm{t}=4.2 \mathrm{~s}$

The schematic of the simulated DFIM system is shown in Fig. 5. In all of the cases, the three-phase fault resistance is $0.5 \mathrm{~m} \Omega$. The stator active and reactive power in this study is depicted in Fig.6. As it can be seen, when there is a fault in rotor windings or near the rotor side converter (cases 1 and 2 ), the machine absorbs reactive power and the injected power to grid increases due to the machine fixed speed. The fault case 1 and 2 have the same effect on the stator side. Therefore, the performance of the stator active and reactive power for these two cases are almost the same. Hence, the internal and external fault in the rotor cannot be distinguished from the stator active and reactive powers.

The three-phase rotor current and the rotor side converter current are displayed in Fig.7 and Fig.8, respectively. The three-phase stator and the grid currents are shown in Fig. 9 and Fig. 10, respectively. As it can be seen, when there is an external fault or internal fault in the stator, the rotor current will increase, having both similar values. This indicates that the fault in the stator will induce same effect in rotor current never mind whether it is external or internal. Moreover, the stator current for internal and external fault in the rotor is the same in both cases, as it can be seen in Fig. 9 and Fig. 10.

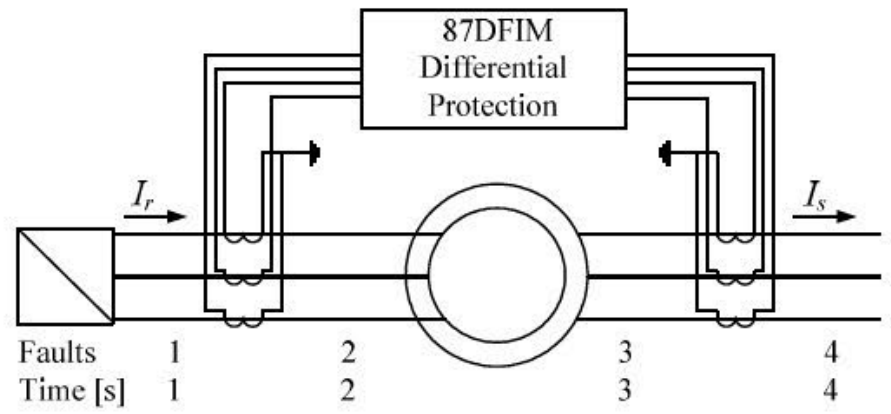

Fig. 5. Performed faults in the DFIM at 1,2,3 and $4 \mathrm{~s}$ (1. External rotor fault/ 2. Internal rotor fault / 3. Internal stator fault / 4. External stator fault).

Therefore, the internal and external faults cannot be distinguished by only using the rotor or the stator currents. Additionally, according to Fig. 8 and Fig. 10, the converter currents and the grid currents increase during both internal and external faults. However, it does not clarify which kind of fault has occurred.

The rotor currents in $\mathrm{d}$ and $\mathrm{q}$ axes are shown in Fig.11 and Fig.12, respectively. In all these cases, the rotor current in the synchronous frame has big values during the faults and cannot give any information about the fault. The stator currents in dq synchronous frame are shown in Fig.13 and Fig.14, respectively. In these figures, although the $\mathrm{d}$ axis stator current in the fault case 3 has a big value if compared to the other cases, the $\mathrm{q}$ axis stator current has a big value in cases 1 and 2 . This high current in the $q$ axis shows that the stator is absorbing a lot of reactive power from the grid. According to Fig.11 to Fig.14, the rotor and stator currents are increased during the fault in dq axis. However, these currents also do not show the type of the fault.

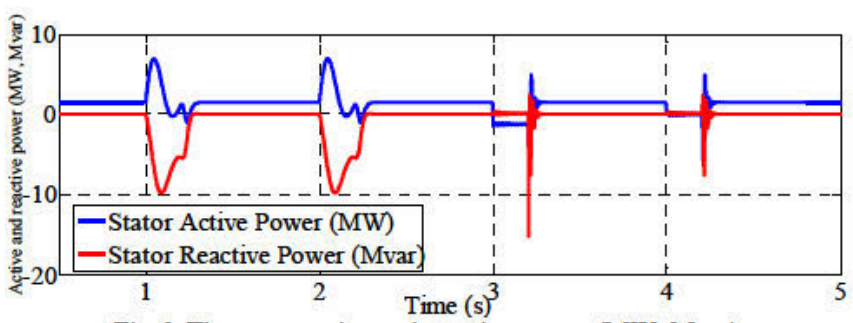

Fig.6. The stator active and reactive power (MW, Mvar)

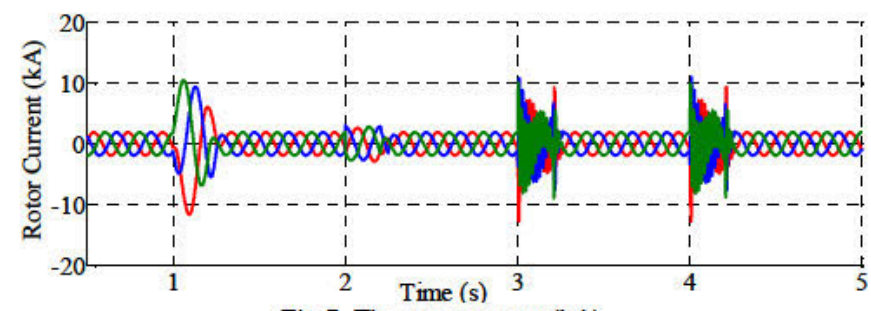

Fig. 7. The rotor current $(\mathrm{kA})$



Fig.8. The rotor side converter current $(\mathrm{kA})$

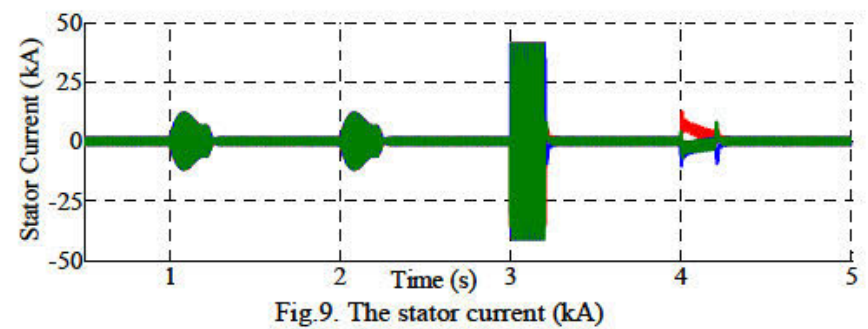

The differential currents in dq synchronous frame are shown in Fig.15 and 16. According to these two figures, the differential current in synchronous frame is almost zero during normal operation with the external fault. However, during the internal fault, the differential currents in dq have a big value. Hence, these two figures clearly show that when 
there is an internal fault in the induction machine (case 2 and 3 ), the differential currents are high and when there is an external fault in the system, the differential currents are small (case 1 and 4). These two figures obviously indicate that the differential currents of the rotor and the stator in the synchronous frame could be used to protect the doubly fed induction machines during internal faults. Moreover, when there is an external fault in the system such as the case 1 and 4 , the proposed differential protection of induction machine will not trip.
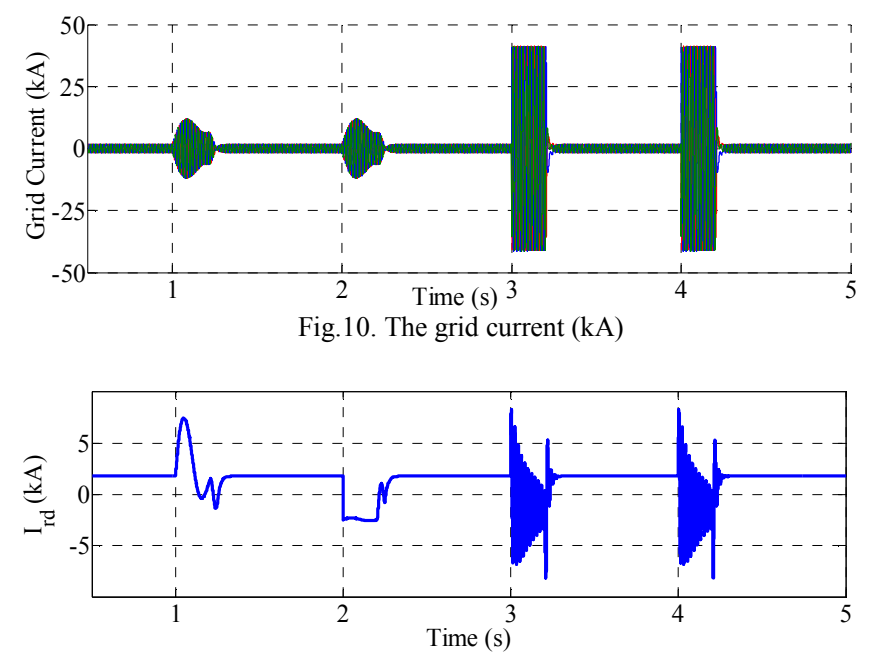

Fig.11. The rotor current in $\mathrm{d}$ axis $(\mathrm{kA})$



Fig.12. The rotor current in $\mathrm{q}$ axis $(\mathrm{kA})$



Fig.13. The stator current in $\mathrm{d}$ axis $(\mathrm{kA})$

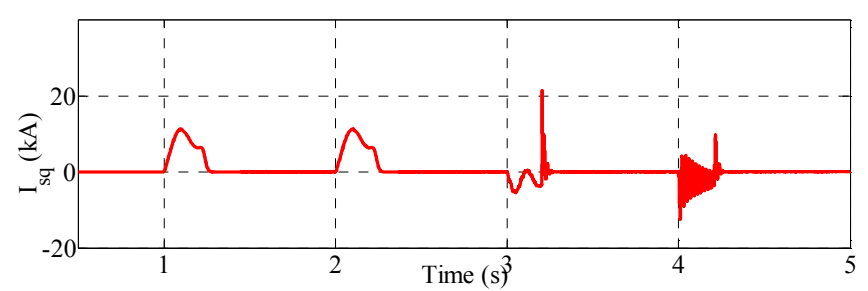

Fig.14. The stator current in $\mathrm{q}$ axis $(\mathrm{kA})$

Fig.16 shows that the differential current in $\mathrm{q}$ axis has a small value during the normal operations. This small current is for magnetization of the machine.

As a result, the proposed differential protection can be implemented in a doubly fed induction machine to prevent damages inside the machine.

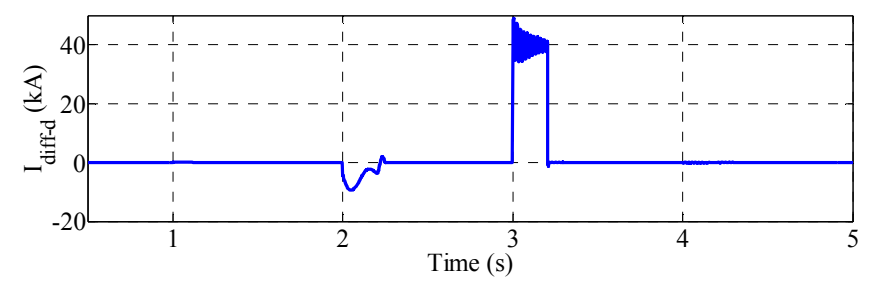

Fig.15. The differential current in $\mathrm{d}$ axis (kA)

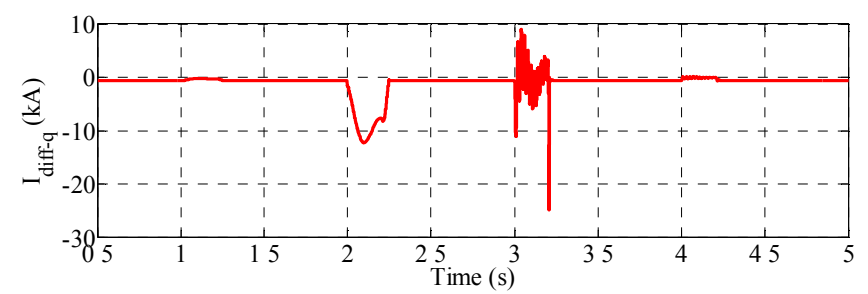

Fig.16. The differential current in $\mathrm{q}$ axis $(\mathrm{kA})$

\section{CONCLUSIONS}

The protection of the rotor of a DFIM is not an easy task due to the low frequency of the rotor current during normal operation. Hence, the usual protection for the rotor cannot be effective and fast due to the variable low frequency. However, this paper, presents a simple and practical differential protection for the DFIM based on the comparison of the Id and Iq of the rotor and the stator, which consideres the low frequency of the rotor current. The results show that the proposed protection can protect the rotor and the stator windings during internal faults but without tripping in case of external faults.

\section{APPENDIX}

TABLE. A1. PARAMETERS OF SIMULATED DFIM

\begin{tabular}{cc|cc}
\hline \multicolumn{4}{c}{ Parameters of simulated DFIG } \\
\hline \hline Rated power & $2 \mathrm{MW}$ & $\mathrm{L}_{\mathrm{m}}$ & $3.362 \mathrm{pu}$ \\
Rated voltage & $690 \mathrm{~V}$ & DC link nominal voltage & $1200 \mathrm{~V}$ \\
$\mathrm{R}_{\mathrm{s}}$ & $0.0108 \mathrm{pu}$ & Number of pole pairs & 2 \\
$\mathrm{R}_{\mathrm{r}}$ & $0.0121 \mathrm{pu}$ & Lumped inertia constant & 0.5 \\
$\mathrm{~L}_{\mathrm{ls}}$ & $0.102 \mathrm{pu}$ & Grid frequency & $50 \mathrm{~Hz}$ \\
$\mathrm{~L}_{\mathrm{lr}}$ & $0.11 \mathrm{pu}$ & $\mathrm{N}_{\mathrm{s}} / \mathrm{N}_{\mathrm{r}}$ & 0.333 \\
\hline \hline
\end{tabular}

\section{REFERENCES}

[1] ALSTOM: 'Network Protection \& Automation Guide', 2012.

[2] M. E. Zarei, C. Veganzones Nicolás and J. Rodríguez Arribas, "Improved Predictive Direct Power Control of Doubly Fed Induction Generator During Unbalanced Grid Voltage Based on Four Vectors," IEEE Journal of Emerging and Selected Topics in Power Electronics, vol. 5, no. 2, pp. 695-707, June 2017. 
[3] M. E. Zarei, and B. Asaei, "A robust direct current control of DFIG wind turbine with low current THD based predictive approach," Wind Energy, Vol. 19, pp. 1181-1199, July 2016.

[4] M. Ebrahim Zarei and B. Asaei, "Combined vector control and direct power control methods for DFIG under normal and unbalanced and distorted grid voltage conditions," 4th Annual International Power Electronics, Drive Systems and Technologies Conference, pp. 107-112, Tehran, 2013.

[5] M. A. Bidgoli, H. A. Mohammadpour and S. M. T. Bathaee, "Advanced Vector Control Design for DFIM-Based Hydropower Storage for Fault Ride-Through Enhancement," IEEE Transactions on Energy Conversion, vol. 30, no. 4, pp. 1449-1459, Dec. 2015.

[6] M. Persson and P. Chen, "Frequency control by variable speed wind turbines in islanded power systems with various generation mix," IET Renewable Power Generation, vol. 11, no. 8, pp. 1101-1109, 628 2017.

[7] R. Jiang, J. Wang and Y. Guan, "Robust Unit Commitment With Wind Power and Pumped Storage Hydro," IEEE Transactions on Power Systems, vol. 27, no. 2, pp. 800-810, May 2012.

[8] C. An et al., "Design and testing of a new protection relay for variable speed DFI motor generators," 12th IET International Conference on Developments in Power System Protection (DPSP 2014), Copenhagen, pp. 1-6, 2014.

[9] A. Wechsler, G. Perugini, A. Schwery, J. M. Guerin, G. Lloyd and B. Kawkabani, "The development of a novel rotor protection for large doubly-fed induction machines," 2014 International Conference on Electrical Machines (ICEM), pp. 1670-1676, Berlin, 2014.

[10] M. E. Zarei and B. Asaei, "Predictive direct torque control of DFIG under unbalanced and distorted stator voltage conditions," 2013 12th International Conference on Environment and Electrical Engineering, Wroclaw, pp. 507-512, 2013.

[11] X. Y. Xiao, R. H. Yang, X. Y. Chen and Z. X. Zheng, "Integrated DFIG Protection With a Modified SMES-FCL Under Symmetrical and Asymmetrical Faults," in IEEE Transactions on Applied Superconductivity, vol. 28, no. 4, pp. 1-6, June 2018.

[12] D. W. Xiang, L. Ran, P. J. Tavner, and S. Yang, "Control of a doubly fed induction generator in a wind turbine during grid fault ridethrough," IEEE Trans. Energy Convers., vol. 21, no. 3, pp. 652-662, Sep. 2006

[13] J. Morren and S. W. H. de Haan, "Ride through of wind turbines with doubly-fed induction generator during a voltage dip," IEEE Trans. Energy Convers., vol. 20, no. 2, pp. 435-441, Jun. 2005.

[14] Y. K. Gounder, D. Nanjundappan, and V. Boominathan, "Enhancement of transient stability of distribution system with SCIG and DFIG based wind farms using STATCOM," IET Renew. Power Gener., vol. 10, no. 8, pp. 1171-1180, Sep. 2016.

[15] D. Ramirez, S. Martinez, C. A. Platero, F. Blazquez, and R. M. de Castro, "Low-voltage ride-through capability for wind generators based on dynamic voltage restorers," IEEE Trans. Energy Convers., vol. 26, no. 1, pp. 195-203, Mar. 2011.

[16] Q. Huang, X. Zou, D. Zhu, and Y. Kang, "Scaled current tracking control for doubly fed induction generator to ride-through serious grid faults," IEEE Trans. Power Electron., vol. 31, no. 3, pp. 2150-2165, Mar. 2016.

[17] G. Pannell, B. Zahawi, D. J. Atkinson and P. Missailidis, "Evaluation of the Performance of a DC-Link Brake Chopper as a DFIG LowVoltage Fault-Ride-Through Device," in IEEE Transactions on Energy Conversion, vol. 28, no. 3, pp. 535-542, Sept. 2013.
[18] M. A. Rahman and B. Jeyasurya, "A state-of-the-art review of transformer protection algorithms," in IEEE Transactions on Power Delivery, vol. 3, no. 2, pp. 534-544, Apr 1988.

[19] J. A. Kay, D. C. Mazur and K. D. Mazur, "Differential Protection With Critical Motors and Motor Applications: What You Didn't Know," in IEEE Industry Applications Magazine, vol. 23, no. 6, pp. 62-70, Nov.-Dec. 2017.

[20] G. Abad, J. López, M. Á. Rodríguez, L. Marroyo, and G. Iwanski, Doubly Fed Induction Machine: Modeling and Control for Wind Energy Generation. Hoboken, NJ, USA: Wiley, 2011, ch. 4.

\section{BIOGRAPHIES}

Mohammad Ebrahim Zarei received the B.Sc. degree in electrical engineering from the Iran University of Science and Technology, Tehran, Iran, in 2009, and the M.Sc. degree in electrical engineering from the University of Tehran, Tehran, in 2013. He is currently pursuing the Ph.D. degree with the Department of Electrical and Electronic Engineering, Universidad Politécnica de Madrid, Madrid, Spain. His current research interests include electrical machines and drives, the application of power electronics in renewable energy conversion, pumped storage hydropower plants, the control and operation of wind turbine generators, smart grids and protection of electrical machine.

Carlos A. Platero (M'10) was born in Madrid, Spain, in 1972. He received the Dipl. degree and the Ph.D. degree in electrical engineering from the Universidad Politécnica de Madrid, Madrid, in 1996 and 2007, respectively. From 1996 to 2008, he was with ABB Generación S.A., Alstom Power S.A., and ENDESA Generación S.A., where he was involved in design and commissioning of power plants. In 2002, he began teaching in the Electrical Engineering Department of the Universidad Politécnica de Madrid and joined an energy research group. Since 2008, he has been a full-time Associate Professor.

Carlos Veganzones Nicolás was born in Spain, in 1957. He received the B.Sc. degree in industrial electrical engineering from the Polytechnic University of Catalunya, Barcelona, Spain, in 1982, and the Ph.D. degree in industrial engineering from the Universidad Politécnica de Madrid, Madrid, Spain, in 1990. Since 1985, he has been with the Department of Electrical Engineering, Universidad Politécnica de Madrid, where he has been a Full Professor since 1992. He was the Director, where he was involved in more than 30 research projects. Most of these research contributions were in power electricity generation with renewable energy. He has directed five $\mathrm{Ph} . \mathrm{D}$. theses all related to wind power generation systems and is currently in charge of the research group "Power Generation with Wind Energy," Polytechnic University of Madrid. He has co-authored numerous publications, including eight book chapters, 11 JCR indexed papers, and multiple collaborations at scientific conferences. He is the co-holder of five patents.

Jaime Rodríguez Arribas received the Ph.D. degree in electrical engineering from the Universidad Politécnica de Madrid, Madrid, Spain, in 2000. Since 1992, he has been with the Department of Electrical Engineering, Universidad Politécnica de Madrid, teaching graduate and postgraduate courses in electrical machines and their control. 